https://doi.org/10.22201/cimsur.18704115e.2021.v16.539

\title{
Subjetividades en las estrategias de vida de las familias productoras de palma africana en la microrregión costera de Chiapas
}

\author{
Subjectivities in the Life Strategies of Families that Produce \\ African Palm Trees in the Chiapas State Coastal Micro-Region
}

\author{
Enrique de Jesús Trejo Sánchez \\ (iD) https://orcid.org/0000-0003-3945-1039 \\ El Colegio de la Frontera Sur, México \\ ejtrejos@gmail.com \\ Guillermo S. Valdiviezo Ocampo \\ (iD) https://orcid.org/0000-0001-5007-0398 \\ Universidad Autónoma de Chiapas, México \\ gsvo67@gmail.com \\ Manuel Roberto Parra Vázquez \\ (D) https://orcid.org/0000-0002-3955-7223 \\ El Colegio de la Frontera Sur, México \\ mparra@ecosur.mx
}

Resumen

El interés central de este artículo es analizar los modos de vida de las familias productoras de palma africana en la microrregión costera de Chiapas y mostrar cómo se construyen estrategias de acción colectiva para apropiarse de una mayor parte de los ingresos económicos que genera la actividad. Para el propósito se utilizó el enfoque de Sistemas Territoriales Campesinos (SITCA), que resultó útil para conocer los modos de vida de las unidades familiares. También se realizaron talleres participativos y entrevistas a actores claves (productores independientes y socios de las empresas sociales, así como a los encargados de organismos nacionales). En el trabajo se muestra de qué forma las unidades familiares tienen parcelas diversificadas en las que combinan la producción de palma africana con otras actividades agropecuarias y del sector servicios. Los ingresos provenientes de ese cultivo sirven para incrementar sus capitales y, a la vez, cumplir con sus aspiraciones tangibles e intangibles. Además, las dispone para adaptarse al conjunto de normas y reglas impuestas por los organismos multisituados.

Palabras clave: modos de vida, capital social, acción colectiva, diversificación productiva.

\section{Abstract}

This paper aims to analyze the livelihood of families producing African palm trees in the coastal micro-region of Chiapas State. Its core interest is to demonstrate how strategies for collective action are constructed in order to take possession of most of the income generated by this activity. This analysis is based on the Small-Scale Farmer Territorial System approach (SITCA by its acronym in Spanish), of great use in identifying the livelihood of local family units. In addition to this theoretical approach, participatory workshops and interviews were also conducted with key stakeholders (independent producers and business partners in social enterprises, as well as people in charge of national organizations). This paper demonstrates how local family units have diversified plots of land that combine the production of African palm trees not only with other agricultural farming activities, but also with the provision of services. The income proceeding from these crops serves to increase capital and, at the same time, to reach both tangible and intangible aspirations. Besides, it enables these small-scale farmers to adapt to the set of standards and rules imposed by multi-sited organizations. 


\section{Introducción}

$\mathrm{R}$ eferirse a la palma africana o de aceite (Elaeis guineensis Jacq) en México es aludir a un cultivo agroindustrial en expansión. Actualmente, más de 11000 familias dependen de su producción, distribuida en 52 municipios de los estados de Campeche, Chiapas, Tabasco y Veracruz (Secretaría de Agricultura y Desarrollo Rural, 2020). Chiapas es el estado en el que se identifica la mayor superficie dedicada: 45435.53 hectáreas (Servicio de Información Agroalimentaria y Pesquera, 2020).

La producción de palma ha generado grandes debates. Los estudios dan cuenta, desde diferentes perspectivas teóricas, de los procesos sociales involucrados. Desde la ecología política se analizan los vínculos entre los seres humanos y el medio, y las relaciones de poder en el conocimiento, la producción y la apropiación de la naturaleza (Leff, 2006). Las investigaciones en torno al sistema de palma desarrolladas bajo este enfoque contemplan la dimensión política como una arena de lucha y de acuerdos entre el Estado, la población rural y las empresas en contextos territoriales específicos. Destacan al respecto, entre otros, los trabajos de Castellanos y Jansen (2015; 2016; 2017); Castellanos (2018); Castellanos, Tobar y López (2019) y Delabre y Okereke (2019).

Un ángulo de análisis distinto es el de la restructuración productiva y la cadena de valor, desarrollado por Mosquera y López (2017), Trejo, Valdiviezo y Fletes (2018) e Isaac-Márquez (2021), cuyos trabajos se centran en el estudio de las políticas públicas orientadas a la reconversión productiva y la transformación de la cadena de valor de la palma de aceite en un territorio concreto.

Otra mirada, la de la gobernanza, se dirige a identificar los actores sociales y el papel que desempeñan en el proceso y control del sistema productivo de palma (Trejo y Valdiviezo, en prensa). Este planteamiento describe —más allá de los análisis del régimen alimentario neoliberal que explican la inserción de la agricultura nacional en la economía mundial— cómo los grandes terratenientes, con apoyo de las políticas nacionales y de las corporaciones trasnacionales de agronegocios, han contribuido a introducir un sistema industrial que ha perjudicado a los productores campesinos, como se muestra en Ávila y Albuquerque (2018), Pietilainen y Otero (2018) y Pérez y Villafuerte (2021).

Una perspectiva más desde la que se ha abordado el tema es la de medios de vida, elaborada por Rist, Feintrenie y Levang (2010) ; Hunsberger, Bolwig, Corbera y Creutzig (2014); Rosas, Pat, Pat y Cornelis (2018); Abrams, Pischke, Mesa-Jurado, 
Eastmond, Silva y Moseley (2019) ; y Bennett, Ravikumar, McDermott y Malhi (2019) . En estas investigaciones se hace una cuantificación de los recursos materiales que poseen las unidades familiares para su reproducción y se identifica qué es lo que les permite enfrentar las tensiones y mejorar sus oportunidades. A partir de los medios de vida, ${ }^{1}$ Herrera, Parra, Livscovsky, Ramos y Gallardo (2017) proponen el enfoque de modos de vida, que consiste básicamente en agregar a las condiciones objetivas de las actividades económicas y capitales la interpretación subjetiva respecto de valores y frutos que en conjunto constituyen la base de las estrategias de las unidades domésticas. Esta propuesta es retomada por Trejo, Valdiviezo y Parra (2020) para explicar la gobernanza de la producción de palma de aceite en dos territorios de la Selva de Chiapas.

En este artículo, con base en los modos de vida, se profundiza en el análisis de las subjetividades, en términos de valores y frutos esperados de los productores de palma africana en la microrregión costera de Chiapas. Con «frutos esperados» nos referimos a las subjetividades que tienen las familias campesinas; aludimos a sus anhelos y aspiraciones (véase Figura 6).

\section{Marco teórico conceptual}

En el texto se retoma y adapta el esquema conceptual del Sistema Territorial Campesino (SITCA) propuesto por Parra et al. (2020), que se define como un sistema relacional complejo construido socialmente y que explica que las innovaciones ocurren como resultado de la interacción de tres grupos sociales: el grupo gubernamental-empresarial, los grupos domésticos rurales y el grupo socio-académico, así como del impacto que genera la acción mutua en el paisaje. La perspectiva de los modos de vida queda anidada dentro del SITCA (Parra et al. 2020: 176).

Para este trabajo el SITCA se compone de cinco subsistemas: territorio, paisaje, grupo de productores, grupo político económico y grupo de acción local, ${ }^{2}$ que se retroalimentan y condicionan entre sí.

En este estudio se entiende por territorio «la porción de la naturaleza y, por tanto, del espacio sobre el que una sociedad determinada reivindica y garantiza

\footnotetext{
1 Los conceptos de medios de vida (livelihoods) y modos de vida (lifeways), aunque están relacionados, tienen diferencias importantes. Para abundar sobre medios de vida véanse Chambers y Conway (1991), Department for International Development (DFID) (1999) y Scoones (2009); sobre los modos de vida véanse Herrera et al. (2017) y Parra et al. (2020).

2 Con esta denominación nos referimos a un conjunto de actores que interactúan en el territorio; por su naturaleza de acción pueden ser locales, situados o multisituados. De estos últimos son las ONG internacionales que tienen presencia en varios países, pero también en los espacios específicos, como las empresas sociales y privadas dedicadas al cultivo de la palma.
} 
a todos o parte de sus miembros derechos estables de acceso, de control y de uso [...] de los recursos que ahí se encuentran y que dicha sociedad desea y es capaz de explotar» (Godelier, 1984: 107).

Por su lado, el paisaje se interpreta como «una porción del territorio, tal y como es percibida por su población, siendo su aspecto el resultado de la acción y la interacción de factores naturales y humanos» (Consejo de Europa, 2000); implica procesos de apropiación de una sociedad sobre los derechos de acceso a utilizar los recursos de una porción de la naturaleza; se refiere al conjunto de formas que asume el territorio producto de las reiteradas transformaciones realizadas por la interacción del hombre y la naturaleza.

Estas definiciones, según Mazzoni (2014), son importantes porque recuperan cuatro dimensiones: la física —entendida como una porción del territorio—, la holística y temporal -interpretada como la interacción de fenómenos naturales y sociales que, a lo largo del tiempo, moldean el paisaje-, la subjetiva y la cultural —que se refieren a cómo los habitantes descifran y entienden el territorio-.

El grupo de productores está integrado por familias dedicadas al cultivo de palma que complementan sus ingresos con otras actividades agropecuarias y del sector servicios. El grupo político-económico se compone por las empresas sociales ${ }^{3}$ y privadas; por funcionarios gubernamentales y organismos que establecen normas y reglamentos del sistema productivo. El grupo de acción local se conforma por ONG que tienen incidencia en el territorio, aunque por su ámbito de actuación pueden considerarse multisituados. La adscripción a cada uno de los grupos del sistema no es excluyente, porque algunos de los integrantes de un grupo pueden pertenecer al mismo tiempo a otro, según la función que desempeñen. Por ejemplo, productores individuales que participan en las empresas pertenecen al colectivo, pero también, a su vez, a un grupo político económico.

La acción colectiva es entendida como el «resultado de intenciones, recursos y límites, con una orientación construida por medio de relaciones sociales dentro de un sistema de oportunidades y restricciones» (Melucci, 1991: 358) y posibilita que los individuos también tengan membresía en el grupo, y cuando emprendan procesos de mayor alcance por medio de empresas sociales se les ubique en el nodo político económico. Otro caso semejante es el de organismos internacionales que impulsan reglas y normas de funcionamiento del sistema y, al mismo

\footnotetext{
3 Se entiende por empresa social aquella que surgió de la acción colectiva de los palmicultores para apropiarse de una mayor porción del valor generado en el proceso de extracción de aceites. Entre estas se encuentran: i) Aceitera Chiapaneca La Palma, antes Beneficiadora de Palma del Soconusco, S. A., (BEPASA); ii) Zitihualt; iii) La Primavera y, iv) Oleopalmex, aún en construcción.
} 
tiempo, proporcionan financiamiento para su cumplimiento. Lo anterior supone que pertenecen, al mismo tiempo, al grupo político económico y al grupo de acción local.

El Sistema Territorial Campesino, en conjunto, permite identificar los modos de vida de las familias campesinas que buscan asegurar el acceso a los recursos indispensables, considerados como capitales, para realizar un conjunto de actividades encaminadas a satisfacer sus necesidades, tanto objetivas como subjetivas (Parra et al. 2020). «Los modos de vida de los grupos étnicos hacen referencia a cuatro componentes interrelacionados: la cultura y las subjetividades, sus necesidades y anhelos (materiales e inmateriales), sus estrategias productivas y los medios o capitales con los que cuentan para llevar a cabo cada estrategia» (Vázquez, Parra y Gracia, 2018: 4).

Las subjetividades de los productores se expresan en los valores y frutos esperados, que conducen al actor a construir su propia realidad de forma individual o colectiva y, a la vez, a apropiarse del territorio en el que se proyectan reglas sobre el manejo y uso de los recursos. En sentido genérico, los valores son las propiedades de la cultura, consideradas típicamente positivas y de gran importancia, que permiten establecer relaciones con otros actores del territorio (Parra, 2018:17). Los frutos esperados tienen como base los ingresos en cantidad suficiente para cubrir satisfactores materiales e inmateriales. En este sentido, la importancia de la subjetividad es que recupera, desde la lógica de las unidades familiares, las actitudes, emociones y valores que influyen en las expectativas y en la toma de decisiones (Parra et al. 2020). Es preciso reconocer que en cada territorio se presentan condiciones específicas en términos sociales y productivos y que en la medida en que las relaciones sean más complejas (en términos del número y tipo de actor) resultará más difícil identificar las estrategias y subjetividades de los actores sociales.

En los modos de vida las actividades económicas son las agropecuarias, fundamentalmente el cultivo de palma. Los capitales se entienden desde la definición de Bourdieu como el «trabajo acumulado, bien en forma de materia o de forma interiorizada o incorporada» (2000: 131). El capital puede presentarse en tres maneras: económico, cultural y social. Los capitales permiten a las familias tener distintas subjetividades y, por ende, ejecutar muy diversas estrategias; es decir, en función de sus capitales tienen la posibilidad de definir qué acciones agrícolas implementar.

En este artículo analizamos los modos de vida de las familias dedicadas al cultivo de palma africana en la microrregión costera de Chiapas, que comprende los 
municipios de Mapastepec, Acapetahua y Villa Comaltitlán (en adelante se hace la referencia a este espacio como «microrregión»). Las familias desarrollan prácticas organizativas para acrecentar sus capitales, ya sea de manera individual o colectiva; propician el logro de actividades objetivas y subjetivas a corto, mediano y largo plazos; además, ejercen el control de la palma y su comercialización. Debido a las diferencias en la extensión de tierra para el cultivo de palma africana, cada grupo genera distintas estrategias asociadas con su actividad agropecuaria.

\section{Metodología}

Para analizar el Sistema Territorial Campesino se retoma la metodología utilizada por Parra et al. (2020) en el sentido de identificar los nodos de grupo de productores, grupo político-económico y grupo de acción local, así como su interacción que transforma el paisaje. El primer grupo se integra por unidades familiares que cultivan palma de manera independiente y por aquellas que pertenecen a una empresa social. El segundo, por empresas sociales y privadas, así como por organismos gubernamentales. El tercero, por organismos que inciden en el sistema de palma y cuyo ámbito de acción puede ser local o bien multisituado. El sistema crea un acervo de condiciones en las cuales estas unidades producen sus subjetividades a partir de valores, frutos esperados, actividades económicas y capitales que, en conjunto, construyen sus modos de vida.

La investigación de campo se realizó en la microrregión entre enero y marzo de 2020. Los tres municipios concentran la mayor superficie establecida con palma africana; albergan siete extractoras de aceite y el mayor número de organizaciones (Figura 1).

La información se obtuvo mediante el enfoque metodológico desarrollado por el equipo que publicó el manual «Familia y vida campesina en la frontera sur: caminos de escucha transdisciplinarios» (Cruz, 2018), el cual consiste en generar actividades y guiar una reflexión con las familias sobre los siguientes aspectos: organización familiar, proyectos de vida, patrimonios y capacidades para lograr sus propósitos de bienestar.

Para obtener la información se realizaron 13 talleres participativos, a los cuales asistieron 257 personas de 29 ejidos de la microrregión. De los participantes, 72 $\%$ eran hombres (184) y $28 \%$ mujeres (73). Del total, 132 eran socios de algunas de estas cuatro empresas: Aceitera Chiapaneca La Palma, Zitihualt, La Primavera y Oleopalmex y los 125 restantes eran productores independientes. Dicho en porcentajes: $51 \%$ estaban organizados y $48 \%$ no lo estaban. 
Figura 1. Superficie cultivada con palma africana

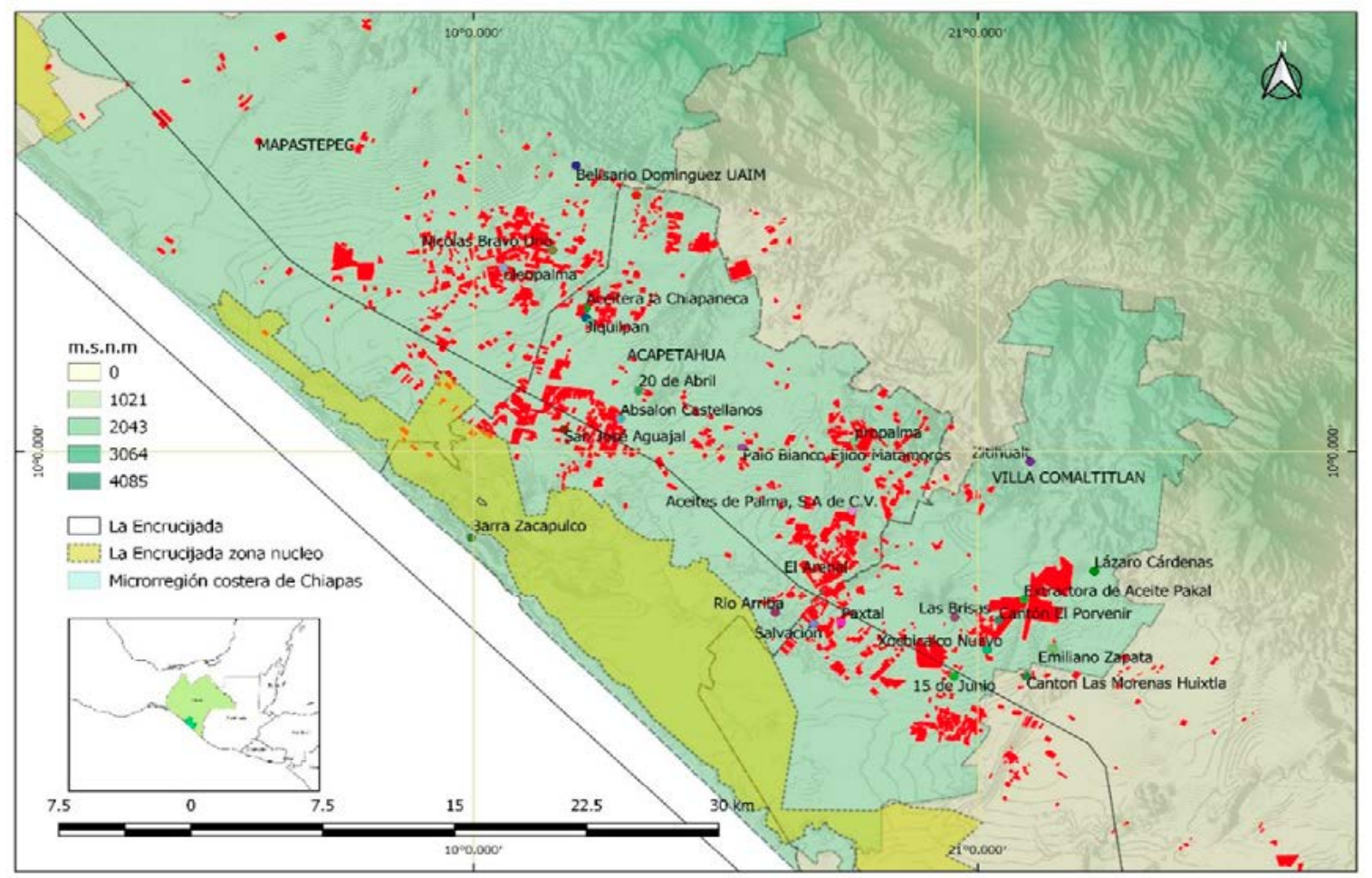

Fuente: elaboración propia con imágenes de satélite RapidEye y foto interpretación de imágenes de satélite de Google Earth.

Para complementar la información se realizaron nueve entrevistas semiestructuradas a actores involucrados en el sistema productivo de palma africana, entre quienes se encontraban los palmeros más antiguos y representantes de organismos gubernamentales. También se interrogó a gerentes de las agroindustrias, servidores públicos y directivos del grupo de acción local. En talleres con grupos focales se entrevistó a pescadores de la Barra Zacapulco, ubicada al interior del Área Natural Protegida de la Reserva de la Biosfera de La Encrucijada. En total se obtuvo información de 285 actores. Para guardar el anonimato de los informantes se utilizan seudónimos al citar sus testimonios.

\section{Sistema de palma y modos de vida}

Apoyados en la metodología propuesta por Parra et al. (2020), los resultados se presentan según cada nodo y se identifican las interacciones.

Grupo de productores. Siguiendo el trabajo de Trejo (2018), en la microrregión existen 3270 personas dedicadas al cultivo de palma africana; los productores se 
clasifican en pequeños, medianos, grandes y muy grandes. Los pequeños tienen una superficie de 0.5 a 5 ha; los medianos tienen entre 5.05 y 50 ha; los grandes poseen de 50.05 a 100 ha, y los muy grandes de 100.05 hasta 1000 ha. Según esta clasificación se identifican 1785 pequeños, con una superficie total de 5345 ha; 21 medianos, con un total de 5835.85 ha; 1435 grandes, con 16532 ha; y 29 muy grandes, que suman 2092 ha.

Por sus características, la clasificación es de tres tipos: al primero se le denomina palmero libre, en lo sucesivo «independiente»: entrega la fruta al mejor postor, no recurre a ninguna asociación y tampoco es socio de alguna extractora. El segundo cuenta con plantaciones y forma parte de alguna organización social que se conforma con el objetivo de tener una planta extractora. En este grupo están también los que producen fruta y comercializan a través de la organización de manera consolidada. El tercero es el productor que cuenta con plantaciones y es a la vez socio de alguna extractora de aceite social como Aceitera Chiapaneca La Palma, Zitihualt, La Primavera y Oleopalmex, esta última en fase de construcción.

Desde la subjetividad, las personas dedicadas a este cultivo se autodefinen y se distinguen entre ellos como palmero y palmicultor. Lo que significa, desde la perspectiva de Bourdieu (2000), que disponen de diferentes tipos de capitales y estrategias para incrementarlos, y eso, al paso del tiempo, profundizará su diferenciación. Al respecto, un líder de palmeros indica:

Palmero es la persona hombre o mujer ${ }^{4}$ que en el palmar se concentra exclusivamente en la recolección del fruto sin realizar ninguna actividad cultural adicional y ve el cultivo como casi silvestre; [en cambio] palmicultor [es la] persona, hombre o mujer, que al interior del palmar realiza todas las actividades culturales y ve en este sistema inversión (M. Fernández, entrevista, municipio de Huehuetán, 14/01/2020).

También en el territorio se asume una distinción entre el palmero y el palmicultor. Los primeros se concentran principalmente en la recolección y venta del fruto y no se involucran en acciones colectivas. Los segundos, por el contrario, realizan procesos de inversión desde el cultivo hasta acciones colectivas que incluyen participar en la construcción de una empresa social.

Otra forma de incrementar los capitales consiste en crear una empresa extractora de aceite. A partir de 1995, los palmicultores se han organizado y en la

4 Algunas de las productoras de palma que pertenecen a las Unidades Agrícolas e Industriales de la Mujer (UAIM) cultivan palma africana y, con excepción del corte y el acarreo del fruto, se ocupan de las demás actividades que implica la administración de sus palmares. 
actualidad existen 25 asociaciones. Ellos, con su gran conocimiento empírico y experiencia, llegan a la siguiente conclusión:

Dedicarse a la palma africana, la verdad, no es negocio; el verdadero negocio de la palma está en la extracción de los aceites; ahí está el verdadero negocio. Es por eso por lo que las empresas privadas se establecen aquí. Es por esta razón que luchamos por tener algún día nuestra propia empresa (P. Martínez, entrevista, ejido Belisario Domínguez, 25/02/2020).

Si bien las organizaciones representan una forma de incrementar el capital social (Bourdieu, 2000), este tipo de asociaciones han enfrentado la dificultad de crear una extractora de aceite por sí mismas. Esta circunstancia las ha conducido a incrementar su capital social a través de nuevos esquemas organizativos como es la conformación de una asociación para integrar la industria Oleopalmex, SAPI de CV. En esta se agrupan ocho organizaciones que, en conjunto, representan a más de 700 socios de siete municipios, que van desde Mapastepec hasta Suchiate.

Como en el periodo de gobierno de Enrique Peña Nieto (2012-2018) este sector recibió poco financiamiento, los palmeros definieron la estrategia de autofinanciamiento por medio de la venta de acciones entre los socios a costo unitario de cinco mil pesos, con lo que buscaban construir su propia empresa. Las formas de organización de los palmicultores les ha permitido crear un capital social y económico que no solo los ubique en el nodo de productores, sino también que los clasifique como empresarios. Esto último los sitúa en el nodo político-económico, con capacidad para negociar con los funcionarios del gobierno.

Participación del grupo gobierno-empresa. Como se ha señalado en distintas investigaciones en las que se analiza el cultivo de la palma africana (Castellanos y Jansen 2017; Trejo, Valdiviezo y Fletes, 2018; Trejo, Valdiviezo y Parra, 2020), este fue impulsado por el gobierno federal y estatal a través del esquema de reconversión productiva, con el objetivo de enfocarse en cultivos más rentables y beneficiar con mayores ingresos económicos a las familias. En el periodo de gobierno en Chiapas de Juan Sabines Guerrero (2006-2012) se pretendió producir biodísel por medio de plantaciones de piñón y palma africana para utilizarlo en el sistema de transporte público de la capital del estado, Tuxtla Gutiérrez (Valero, Cortina y Vela, 2011: 126), sin que se lograran los resultados esperados por razones de costos. Sin embargo, la producción de palma sí se potenció debido a la alta demanda nacional, y se establecieron nuevas plantaciones que alcanzaron 
niveles históricos. En el corredor costero de Chiapas, de 2007 a 2012 se establecieron 26217 hectáreas de palma, lo que representó 63.45 \% del total del cultivo (Trejo, 2018: 123).

En las reglas de operación $(\mathrm{RO})$ del esquema de desarrollo para el campo impulsado por el gobierno federal de Andrés Manuel López Obrador (2018-2024) - a través de la Secretaría de Agricultura y Desarrollo Rural (SADER) - no estaba contemplada la palma africana. Esa omisión obligó a los productores de esta oleaginosa a autofinanciarse. Y aunque el gobernador de Chiapas, Rutilio Escandón Cadenas (2018-2024), tampoco había considerado destinar apoyos gubernamentales para este cultivo, el 3 de marzo de 2020 las organizaciones que representan a las distintas regiones tuvieron la habilidad y capacidad para poner el tema en la agenda pública. Entre los principales acuerdos de estas negociaciones identificamos tres:

Primero, el gobierno del estado de Chiapas se comprometió a ser el vínculo entre la Financiera Nacional de Desarrollo (FND) y los productores para negociar créditos a una tasa de un dígito. Los recursos se otorgarían vía créditos y no a fondo perdido. Segundo, estos debían presentar propuestas para incluirlas en los programas del gobierno del estado. Por último, los funcionarios de la Secretaría de Agricultura y Pesca (SAyP) les brindarían asistencia técnica. ${ }^{5}$

Empresas. Las condiciones fisiográficas que imperan en esta microrregión han propiciado que, a través de iniciativas de los actores (productivos y gubernamentales), se impulse la agroindustria, lo cual ha posibilitado configurar un sistema productivo específico de la palma africana. En tal sistema las extractoras de aceite se han convertido en una pieza relevante en lo económico, en lo normativo y en lo político.

En la microrregión costera se localizan siete empresas que son las que articulan la producción de palma y extracción de aceite; cuatro corresponden al sector privado: Oleopalma, Propalma, Pakal y Aceites de Palma, que inició operaciones en mayo del 2020. Esta última tiene como particularidad que es la única en el sureste de México que contará con un área de refinado. También están presentes tres sociales: Aceitera Chiapaneca La Palma, antes BEPASA, Zitihualt y La Primavera, las cuales agrupan aproximadamente a 750 socios.

El conjunto de normas y reglas del control de calidad que operan en el sistema provienen principalmente de las refinadoras, ubicadas fuera del estado de

\footnotetext{
5 Fuente: reunión de trabajo entre funcionarios del gobierno de Chiapas y productores de palma, en Tuxtla Gutiérrez, Chiapas, 3 de marzo de 2020. Dato obtenido en investigación de campo.
} 
Chiapas, las cuales exigen cierta normatividad a las extractoras chiapanecas. Este procedimiento ha condicionado a su vez la imposición de pautas a los proveedores de fruta, quienes se oligan a entregarla en óptimas condiciones de maduración, esto es, dentro de las 24 horas siguientes al corte; que el racimo no tenga tallo y que se incluyan todas las frutas que se desprendan del racimo en el proceso de corte. En caso de no atender estas recomendaciones se prevén sanciones que van desde la afectación en los precios, es decir, que se les pague más barato, hasta el rechazo del producto.

Las empresas sociales tienen como uno de sus principales objetivos romper la subordinación de los productores ante las privadas. Han identificado que la mayor parte de los beneficios se generan en el proceso de extracción de aceite y no en el cultivo. Para los socios, cumplir con este objetivo se traduce en mejores beneficios en el cultivo y en el proceso de extracción.

A nivel internacional, el precio de los aceites de palma es regulado por la Bolsa de Valores de Rotterdam. En México es definido en la Asociación Nacional de Industriales de Aceites y Mantecas (ANIAME). En el territorio nacional el precio por tonelada de fruta fresca corresponde a $12.5 \%$ del costo de una tonelada métrica de aceite crudo. Precio inferior con respecto a Colombia, que es de 18 $\%$; o a Costa Rica, donde oscila entre $15 \%$ y $16 \%$ (directivos de la empresa La Primavera, entrevista, municipio de Acapetahua, 25/03/2020).

Si bien las empresas sociales y privadas tienen un comportamiento semejante en términos de las normas y los precios de la fruta, la diferencia clave entre ellas radica en que algunas reparten utilidades entre sus integrantes y los proveedores independientes reciben un bono por la fidelidad con el colectivo, así como la garantía de compra más allá de la potencial oferta de fruta en la microrregión.

Grupos de acción local. Son organismos creados para impulsar y gestionar proyectos que surjen de manera descentralizada y desde los territorios. Estos no se circunscriben a consultar a la población sino que involucran una lógica de acción colectiva que va desde la concepción hasta la formulación e instrumentación de los proyectos (Cernea, 1991; Cook, 1991). Sin embargo, en los territorios se pueden identificar organismos que se localizan y que obedecen a una lógica local, pero tambien aquellos que son multisituados y responden a lógicas de procesos que van más allá del territorio. Teóricamente, los organismos multisituados son organizaciones sin fines de lucro que se establecen con la finalidad de coadyuvar en la resolución de problemas por medio de la participación de los actores y el establecimiento de reglas claras que pudieran mejorar las condiciones de vida de la población. 
En el sistema productivo de palma tienen presencia los dos tipos de organismos. En el primero, la asociación civil Ecología, Sustentabilidad e Innovación (ESI) es una consultoría que recibe financiamiento de un organismo multisituado, como es Eartworm, con el proposito de asesorarlos en la conservación de la Reserva de la Biosfera La Encrucijada y los vínculos de cooperación con la Comisión Nacional de Áreas Naturales Protegidas (CONANP). Otros de los organismos multisituados son la Mesa Redonda sobre el Aceite de Palma Sostenible (RSPO, por sus siglas en inglés) y la ONG Solidaridad.

La RSPO es una organización internacional que se propone integrar a los diversos sectores que participan en la industria de palma de aceite con el fin de certificar los procesos del sistema productivo, con una perspectiva de conservación y cuidado del ambiente. La certificación que pretende hacer la RSPO supone cumplir un conjunto de normas y reglas promovidas por este organismo. Los principios que rigen el proceso de certificacion se centran en el comportamiento ético y transparente; las operaciones legales y el respeto a los derechos; la optimización de la productividad, la eficiencia, los impactos positivos y la resiliencia; respeto a la comunidad, los derechos humanos y prestaciones de beneficios; apoyo a la inclusión de pequeños productores; respeto a los derechos y las condiciones laborales; y la protección, conservación y mejora de los ecosistemas y el ambiente (RSPO, 2018: 19).

Si bien la RSPO se pronuncia a favor del cuidado ambiental, es importante mencionar que juega un doble papel al situarse en el grupo político económico cuando establece los principios que norman y regulan el sistema productivo, pero, a la vez, forma parte del grupo de acción local como el organismo certificador. En este segundo escenario se propone articular a los diversos actores para que se construyan los lineamientos de certificación. Sin embargo, gran parte de lo que propone este organismo proviene de la normativa internacional y es impulsado por las empresas que controlan el sistema de producción de aceite de palma a nivel mundial. La definición de estos mecanismos de operación ponen en franca desvetanja a los palmeros.

Por su parte, Solidaridad llega a México con el fin de participar principalmente en dos cadenas: caña de azúcar y palma africana. En esta última realiza contratos de cooperación con Zitihualt, La Primavera y Aceitera Chiapaneca La Palma. El acuerdo consiste en brindar asistencia técnica bajo el formato de escuelas de campo. Además, les ofrece capacitación para lograr la certificación de la RSPO (Solidaridad, 2020). 
No todos participan con Solidaridad, porque consideran que su interés está enfocado en beneficiar a las empresas.

Solidaridad es una organización no gubernamental que tiene como finalidad apoyar a las empresas; sin embargo, como ONG que recibe financiamiento de corporativos internacionales se inclima más por generarle beneficios a quienes le dotan de recursos. Es mentira que le interese el productor; tienen doble moral (M. Fernández, entrevista, cabecera municipal de Huehuetán, 14/01/2020).

De acuerdo con la información de su portal, Solidaridad tiene vínculos con algunos de los corporativos agroalimentarios más grandes a nivel mundial, entre los que destaca la participación de Cargill, Coca-Cola, Unilever, entre otras, e instituciones pronaturaleza como The Natural Conservancy y Norway's Internacional Climate and Forest Initiative.

Por su parte, Eartworm, como fundación, trabaja en la sustentabilidad de cadenas de valor agrícolas, la preservación de los bosques, en la mejora de la situación laboral de los pequeños productores y las condiciones de vida de las familias (Eartworm, 2020). En la Reserva de la Biosfera de La Encrucijada, Eartworm ha comenzado a realizar trabajos con productores para que sustituyan la palma por otros cultivos que tengan menos impacto ecológico y que sean más rentables. Además, está georreferenciando las áreas de bosque para que no se expandan y para que las extractoras no compren la fruta a quienes hayan ampliado su parcela de palma y dismunuido las áreas de bosque.

Al igual que Solidaridad, Eartworm es financiada por corporativos internacionales relacionados con los alimentos, entre los que destacan: Cargill, Nestle, Bimbo, Grupo Rocher, Hershey, Danone, Johnson y Johnson, Fuji Oil, por mencionar algunos (Eartworm, 2020).

Los grupos de acción local se asumen como organismos que representan los intereses de actores locales individuales o colectivos. Sin embargo, en el caso de los grupos multisituados como RSPO, Solidaridad y Eartworm, juegan un doble papel; por un lado, promueven una normativa que, dicen, «busca proteger las condiciones ambientales del territorio, la participación de los pequeños productores y la mejora en sus modos de vida», y por el otro crean una imagen menos negativa para beneficiar a las procesadoras de aceites, a los corporativos refinadores y a las grandes trasnacionales alimentarias. En concreto, estos organimos multisituados desempeñan un papel de juez y parte porque establecen las normas de certificación, pero también son las certificadoras. 
Si bien México cuenta con distintas dependencias gubernamentales cuya responsabilidad es normar la cadena de palma africana, estas se muestran indiferentes y no asumen el papel que les corresponde, tal como lo indica Trejo (2018). Esta situación contribuye a que se pretenda dar la regulación por medio de organismos internacionales, como es el caso de la RSPO, Solidaridad y Eartworm. Si consideramos que en la actual administración estatal (2018-2024) este cultivo se ha retomado en la agenda pública, el papel protágonico seguriá determinado por los grupos de acción local.

\section{Modos de vida de los grupos de productores}

Para los modos de vida se parte del análisis de la rentabilidad de la producción de palma. El rendimiento promedio de fruta fresca obtenido en una hectárea es de 22 toneladas. Si el precio promedio de venta registrado en 2019 fue de 1423 pesos por tonelada, se obtienen en promedio por año 31306 pesos. A este importe deben restarse, por costos de producción, 19668 pesos. Mientras que de mano de obra se hizo el cálculo de 12137 pesos. Los gastos de flete ascienden a 4471 pesos y para fertilizantes se destinan 3059 pesos. Para las integrantes de la Unidades Agrícolas e Industriales de la Mujer (UAIM) también se invierte en el rubro denominado «viáticos».

En un año, la diferencia entre el ingreso obtenido y los costos de producción dan como resultado 11637 pesos de utilidad por una hectárea. De esta cantidad, $63.90 \%$ es destinado a cubrir los costos de producción; de estos, $38.76 \%$ corresponderá a inversión en mano de obra, $14.28 \%$ al flete; $9.71 \%$ a fertilizantes y 0.06 \% para cubrir los viáticos.

Los costos de producción representan el total de erogaciones que el productor tiene que efectuar si paga mano de obra y fletes. Durante la investigación de campo, en la realización de los talleres, los palmeros dijeron que ellos efectúan las faenas para aplicar fertilizantes, hacen el corte, acarreo y traslado de la fruta a los centros de acopio. Para estas actividades utilizan su propio vehículo, para «disminuir» costos. Ellos consideran que así «ahorran» y pueden incrementar la utilidad. Es importante mencionar que no todos pueden realizar esto por cuenta propia, sobre todo los adultos mayores y las mujeres productoras de palma bajo el esquema de las UAIM.

Si bien los asistentes al taller mostraron sorpresa al concer el valor de su utilidad, admitieron que aunque obtienen pocas ganancias, esta actividad les genera 
mayor ingreso que la ganadería y la producción de mango. También mencionaron que son conscientes de que el cultivo supone cubrir más de 50 \% de los costos de producción. En otros términos, los palmeros diversifican en las actividades agropecuarias. Cada productor realiza un cálculo de rentabilidad y define qué hace.

Antes de la palma tenía ganado, pero el ganado implica como mínimo una hectárea para cada animal; también lleva realizar muchos gastos, y al precio que está el kilo no resulta; y si se enferman y mueren los animales, la pérdida se incrementa. Con la palma obtenemos las mismas ganancias que con el ganado, solo que teniendo menos superficie de tierra (J. Vázquez, entrevista, ejido San José Aguajal, Acapetahua, 23/03/2020).

Al igual que lo que ocurre en la ganadería, en la producción de mango se requiere cubrir altos costos de producción y enfrentar el riesgo de la pérdida por causa de fenómenos meteorológicos y por las condiciones de oferta y demanda del mercado.

Producir mango es dedicarse a una actividad que quienes se benefician son los acopiadores. Para tener ganancias es necesario invertirle mucho dinero en químicos para adelantar la floración, es la única manera de sacar la cosecha y tener buen precio. Es un cultivo de mucho riesgo por los huracanes (sic). (investigación de campo, taller realizado en la empresa La Primavera, Acatepahua, 25/03/2020).

Según la disponibilidad de tierra y la racionalidad económica, las familias definen qué será lo preponderante a realizar. En la investigación de campo pudimos identificar un alto grado de diversificación. La prioridad es la palma, seguida de la producción de mango, cacao, maíz y cría de ganado, entre las más importantes; pero quienes tienen poca tierra se concentran únicamente en la palma africana.

\section{Ingresos y su distribución}

Los asistentes a los talleres refieren que la palma es un cultivo estacional. La cosecha tiene su punto crítico entre marzo y agosto (Figura 2). En los meses de menor rendimiento por hectárea obtienen de 250 a 350 kilogramos, lo que los obliga a completar sus ingresos con la venta de otros cultivos. Como hemos mencionado, solo realizarán estas actividades aquellos que cuenten con tierra. Las familias 
generan distintas estrategias a fin de obtener el mayor ingreso económico posible y, en un corto o largo plazo, alcanzar los frutos esperados. Las personas que poseen menos de 1.5 ha optan por alquilar su fuerza de trabajo como cortadores de fruta para completar su ingreso.

Figura 2. Estacionalidad de la producción de fruta de palma africana

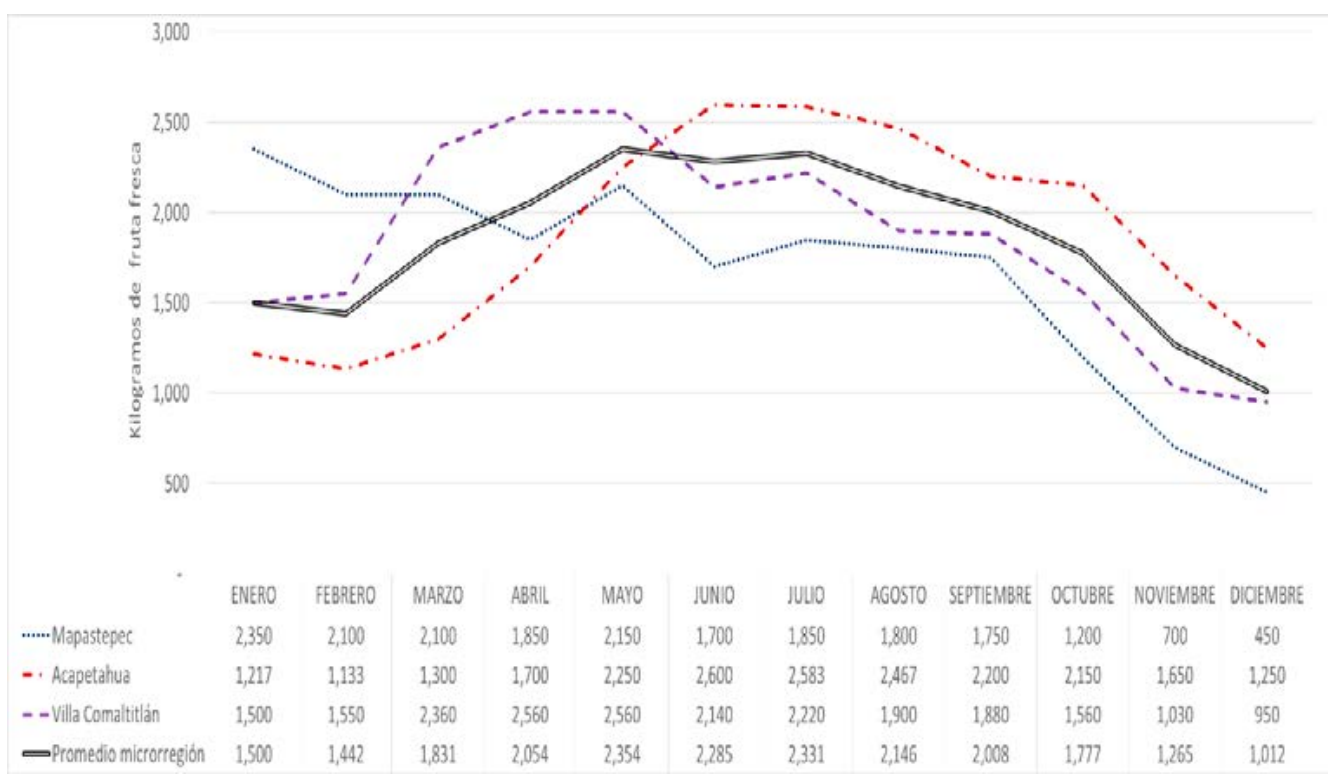

Fuente: elaboración propia con información recabada en los 13 talleres realizados en la microrregión costera, del 9 al 26 de marzo de 2020.

Por la estacionalidad de este cultivo, las familias sustentan sus distintos modos de vida en cinco actividades: agricultura, ganadería, pesca, servicios y como jornaleros en el corte de fruta.

Del sector agropecuario obtienen 82 \% de sus ingresos. Si bien su principal actividad está enfocada en la producción y comercialización del fruto de la palma, esto solo representa 59 \% de sus ingresos monetarios. Además, complementan con la siembra de maíz, plátano, mango, cacao, frijol, caña de azúcar, ajonjolí, nance, además de la crianza y el cuidado de ganado y la pesca. Y $18 \%$ de sus ingresos provienen de otras fuentes (Figura 3). Al respecto, los asistentes a los talleres comentaron:

Los que tenemos palma de aceite podemos también cultivar otras cosas y, en la medida de la superficie, comprar unos animales. El mango es de riesgo porque para 
salir bien hay que invertir en químicos para adelantar la floración y tener buen precio. Podemos decir que es un cultivo de riesgo, si está bien el precio se gana y si no, se pierde; se da el caso de mejor no cortar y que se pudra, sale más caro cortar, al fin que el coyote es el que gana. Con la sandía nos ha pasado que un año la cosecha es buena y se gana, lo que motiva a sembrar más, el segundo año se gana y sembramos más, pero el tercer año resulta que invertimos todo lo que antes ganamos y ¿qué pasa? Se pierde todo, todo. Para pagar las cuentas, los que no tienen palma tienen que vender todo, hasta la parcela [...] se quedan sin dinero para comer [...]. Los que tenemos palma podemos hacer la siembra y si perdemos, cuando menos está la palma que nos da para comer, pero no quedamos con deudas (A. Aguilar, entrevista, ejido Sesecapa, Mapastepec, 25/02/2020).

A diferencia de otros países como Malasia e Indonesia, donde la palma se ha convertido en un monocultivo, en la microrregión se observa cierto grado de diversificación en las parcelas asociado con las estrategias que desarrollan las familias en función de la escala productiva y de la estacionalidad. Las familias afrontan los riesgos que implica producir otras variedades de alimentos porque garantizan la mayor parte de sus ingresos con este cultivo.

Las familias dedicadas a la producción de palma africana tratan de aprovechar al máximo la superficie de tierra con la que cuentan. En las imágenes de la propiedad del Sr. Rafael Orantes se observa una parcela diversificada (Figura 4). La tierra está distribuida de la siguiente manera: 1.5 hectáreas de palma africana; mango variedad ataulfo 1.5 ha; con plátano tiene media hectárea y de piña una cuerda (las medidas de la cuerda son $25 \times 25$ m). En el estado de Campeche, otro producto asociado con el monocultivo es la soya; también se realizan prácticas con cierto grado de diversificación productiva. Una vez cosechada la soya, cultivan maíz y sorgo. En la microrregión costera, la soya también representa una estrategia de supervivencia (Echanove, 2016).

La distribución del ingreso refleja las preocupaciones de las familias por cubrir los satisfactores más importantes, lo que implica efectuar una planificación de las estrategias en sus modos de vida en el corto, mediano y largo plazos. El 89 \% de la distribución del gasto se concentra en cuatro rubros. Los costos de producción absorben 53 \%; los satisfactores alimentarios, 18 \%; mientras que la educación equivale a $11 \%$ y para servicios de salud se destina el $7 \%$ restante. 
Figura 3. Fuentes de ingreso de la unidad familiar en la microrregión costera de Chiapas

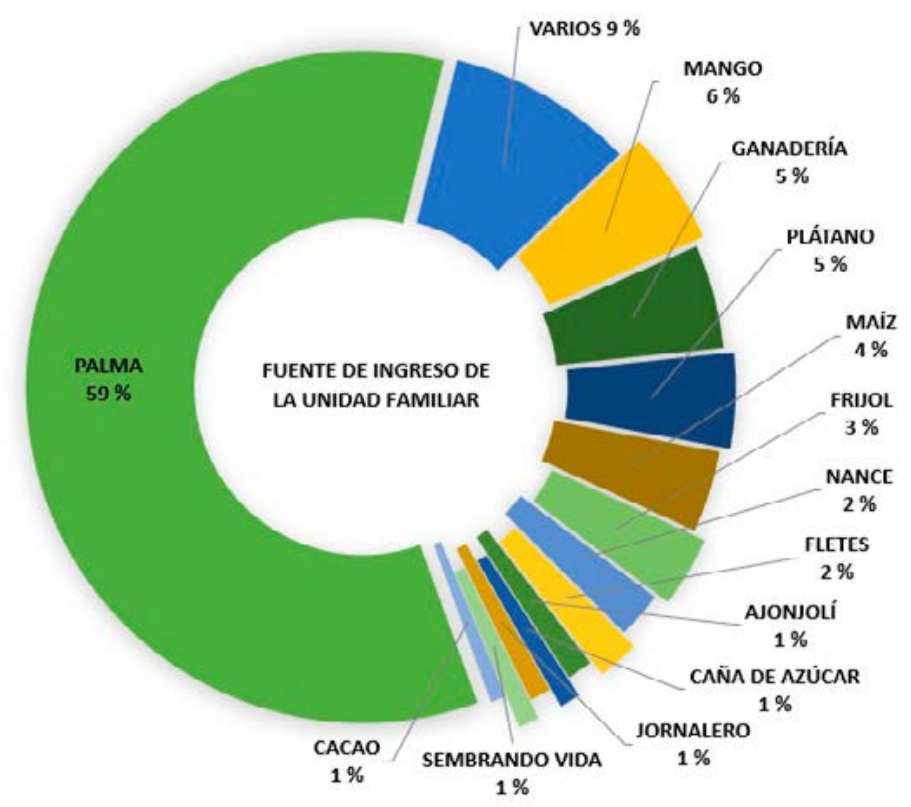

Fuente: elaboración propia con resultados de los 13 talleres realizados en la microrregión costera, del 9 al 26 de marzo de 2020.

Figura 4. Distribución de la tierra de un productor promedio con una superficie de 3.5 ha (mínima)

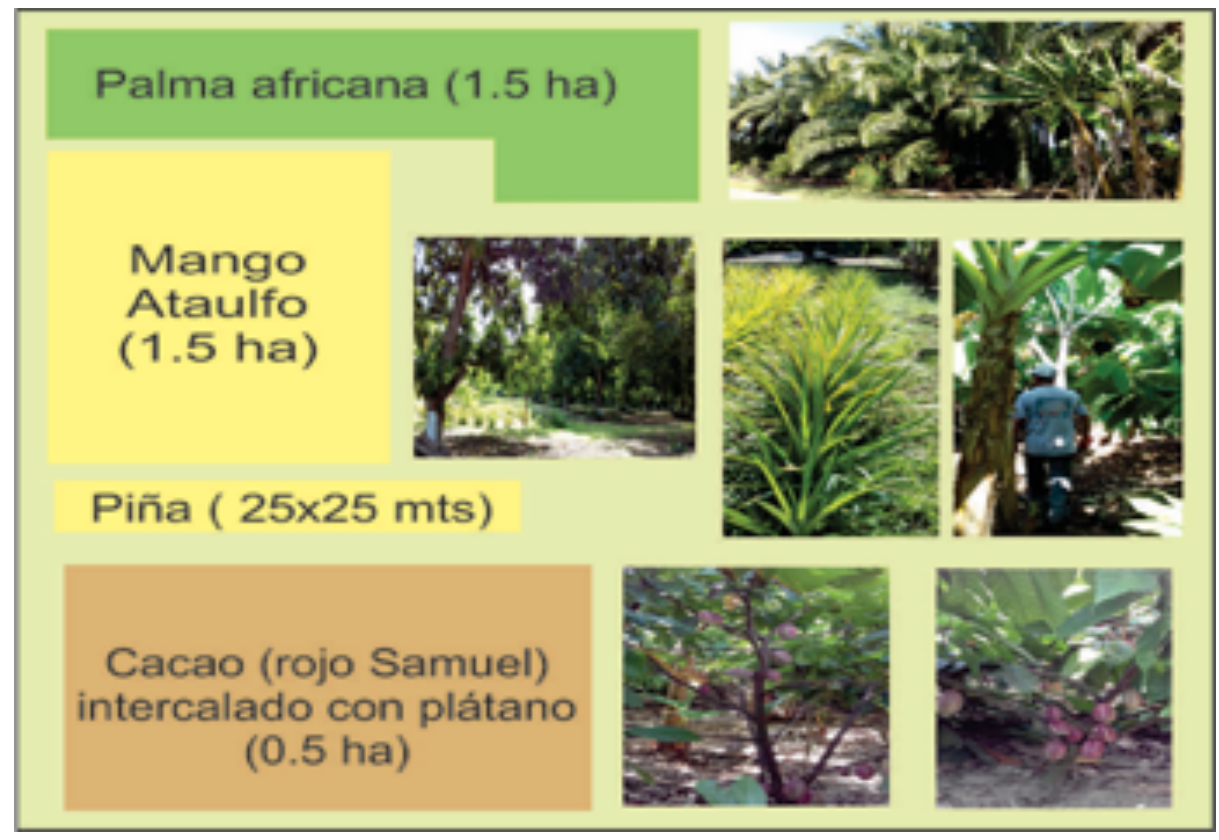

Fuente: imagen de archivo personal del predio del Sr. Rafael Orantes, ejido Xochicalco, municipio de Villa Comaltitlán, 8 de marzo de 2020. 
Desde la subjetividad de las familias, los rubros que tienen especial importancia son educación y servicios de salud. Se considera que la educación es una inversión a largo plazo y los gastos de salud son indispensables para mantener las condiciones físicas necesarias para realizar el trabajo (Figura 5).

Figura 5. Distribución del gasto de la unidad familiar en la microrregión costera de Chiapas

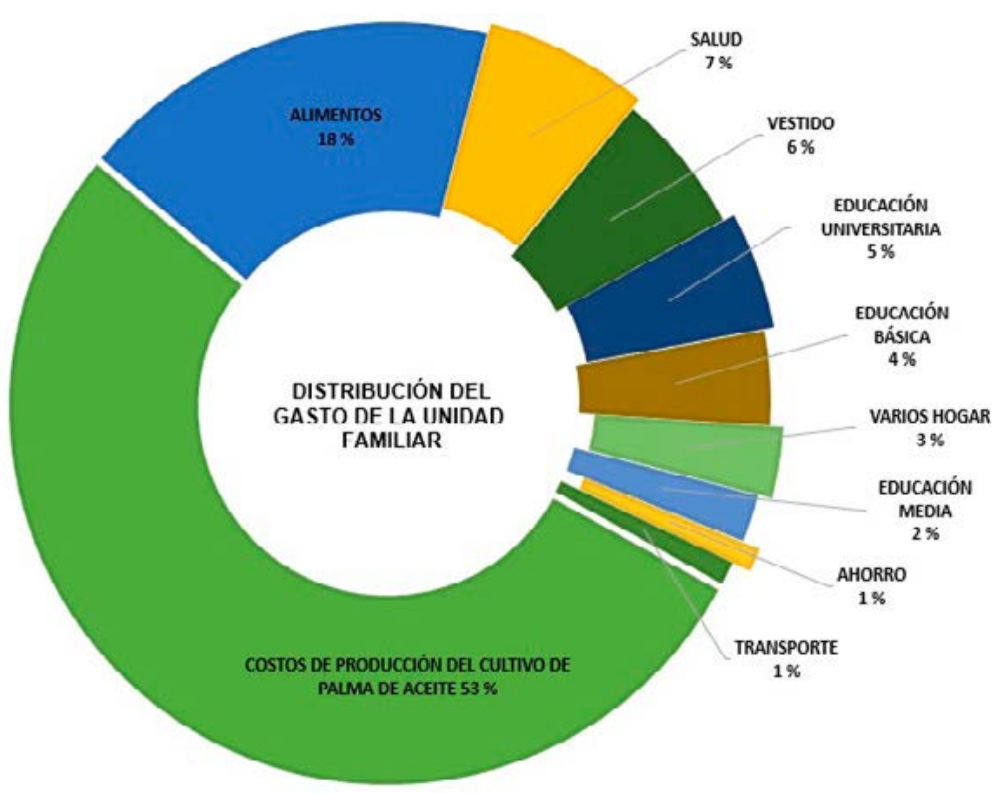

Fuente: elaboración propia con resultados de los 13 talleres realizados en los municipios de la microrregión costera, del 9 al 26 de marzo de 2020.

Para las unidades familiares, dedicarse a este cultivo representa la posibilidad de expandir el horizonte educativo de los hijos, desde el nivel básico hasta el universitario.

Nosotros no tuvimos la oportunidad de ir a la escuela. Gracias a la palma algunos tenemos poco y otros mucho. Ahora podemos mandar a nuestros hijos a la universidad; si tenemos poco los mandamos por acá cerca; los que tienen un poquito más [de dinero pueden ir] lejos. Algunos hijos de productores son ingenieros o están estudiando en la universidad, todo gracias a la palma. Como estudian para ingenieros, cuando regresan trabajan en los molinos, en las empresas; muchos hijos de socios ahí trabajan; esperemos que al final sean buenos hijos y nos ayuden (...) pues ya estamos grandes (A. Cruz, entrevista, ejido Paxtal, Villa Comaltitlán, 11/03/2020). 
A partir de esta forma de pensar es que los capitales sociales, económicos, culturales y naturales se incrementan, porque invertir en educación redunda en cambios no solo para quien ha estudiado, sino también para las familias. Cuando los jóvenes concluyen los estudios universitarios regresan y modifican sus hábitos y también la forma de concebir el medio biofísico. Así lo narra un universitario:

Estudié en la UNACH [en la sede] de Huehuetán. Soy ingeniero agrónomo. Ahora que he regresado a mi ejido estoy más comprometido porque sé cómo hacer mejor las cosas, cómo tener un mejor futuro. Al trabajar en las extractoras [de palma] compartimos el conocimiento con los presidentes de las organizaciones que no tienen estudios; damos nuestra opinión y es tomada en cuenta. En la familia queremos tener una mejor vida (F. Aguilar, entrevista, ejido Jiquilpan, Acapetagua, 17/03/2020).

Al carecer de certeza ante una posible enfermedad que requiera atención especializada, las familias reservan recursos para prevenir ese tipo de gastos que no cubrirá el sistema de salud pública. Los palmicultores de la microrregión se expresan en tal sentido.

Como campesinos no tenemos seguro de vida [sonríen], tenemos que ahorrar para cubrir una enfermedad. Toda enfermedad, por sencilla, sale cara. Tenemos que pagar hospital, trasladarse a Tapachula o Tuxtla Gutiérrez. Aquí las clínicas solo son para morir (sic). Si te enfermas y no tienes ahorro tienes que vender lo que tengas: animales, si tienes; si no, tu parcela; y si te va bien, empeñarla nada más para sacar los gastos (información obtenida en el taller, ejido Jiquilpan, Acapetahua, 25/03/2020).

Desde la perspectiva de las unidades familiares, después de cubrir los costos de producción, el gasto se orienta a alimentación, educación y salud; esta distribución se asocia con sus subjetividades.

\section{Estrategias y subjetividades de los grupos de productores}

Para comprender las estrategias y subjetividades se utiliza la estructura analítica del trabajo de Trejo, Valdiviezo y Parra (2020) (Figura 6). Las estrategias de las familias se entienden a partir de cuatro componentes, dos de carácter subjetivo referidos a los valores y frutos esperados y dos de carácter objetivo, como son las actividades económicas y los capitales. Los cuatro, en conjunto, permiten com- 
prender las transformaciones en los modos de vida y en la apropiación territorial (Vázquez, Parra y Gracia, 2018).

Las familias expresaron la importancia que tienen los siguientes valores: respeto, honestidad, responsabilidad, tolerancia y fidelidad, porque les permiten relacionarse y tener una sana convivencia con los habitantes del ejido. El respeto depende, en gran medida, de los principios fomentados en el seno familiar. Como actitud, fortalece el desarrollo de estrategias de vida que permiten alcanzar los diferentes objetivos a corto, mediano y largo plazos del quehacer personal, social y económico.

Figura 6. Estrategias de vida de las familias productoras de palma africana

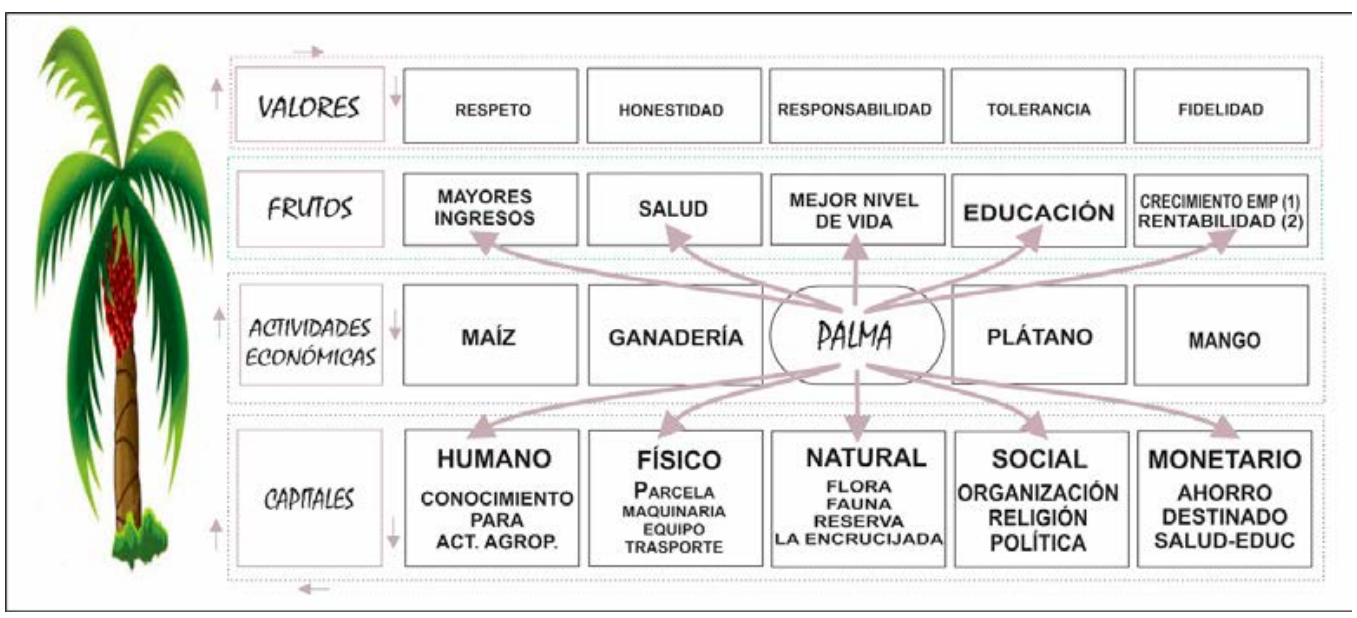

Nota. (1) socios de una empresa extractora aspiran a que la empresa crezca. (2) productores independientes y socios pretenden que sus plantaciones sean más rentables.

Fuente: elaboración propia con información de los 13 talleres realizados en la microrregión costera, del 9 al 26 de marzo de 2020.

Valores. Desde la subjetividad, el valor más importante a desarrollar es el del respeto, seguido de la honestidad, la responsabilidad, la tolerancia y la fidelidad. Los palmicultores consideran que sin estos valores les será difícil convivir y lograr un desarrollo. En 1995, con la creación de la primera empresa social se generaron una serie de disputas. Así lo narra un informante:

Cuando llegó la primera empresa extractora de aceite aquí en el ejido El Arenal, fue mucho pleito, la empresa se convirtió en un botín. Todos querían estar en la directiva para aprovecharse del recurso; se perdió el respeto entre hijos y padres; para terminar pronto, entre familiares y conocidos. Incluso llegaron a sacar armas y machetes para 
matarse. No trabajar con orden llevó a la ruina, esa es la verdad; la empresa se vendió; cuando eso ocurrió agradecimos a Dios. De no venderla estuviéramos lamentado muchos muertos (sic). Con la venta de la planta la comunidad volvió a su calma. (F. Pascasio, entrevista, ejido El Arenal, Acapetahua, 25/03/2020).

A diferencia de lo que ocurrió con las familias del ejido El Arenal, en el de Jiquilpan, en el mismo año, se creó BEPASA. Se fundó, según sus socios, a partir del desarrollo de un conjunto de valores que incluían respeto, honestidad, responsabilidad, tolerancia y fidelidad. Esta situación les ha permitido transformar su unidad productiva. Inicialmente se procesaban seis toneladas de racimos de fruta fresca por hora; sin embargo, actualmente, con la planta industrial denominada Aceitera Chiapaneca La Palma, se procesan 18 toneladas cada hora.

La empresa sirvió como una referencia en la microrregión. Después de ella se crearon 25 asociaciones de palmicultores con la intención de tener su propia extractora. Tres de ellas logran su objetivo: Aceitera Chiapaneca La Palma, Zitihualt y La Primavera. Mientras que ocho (con presencia de siete municipios) se asociaron para construir Oleopalmex. Los valores son un elemento importante para impulsar proyectos de envergadura.

Para los palmicultores, las empresas sociales representan el ejemplo de responsabilidad para quienes pretendían tener una extractora. Sin embargo, este compromiso no siempre es compartido por los miembros de Oleopalmex. Al respecto, algunos socios se expresan de la siguiente manera:

Estamos intentando conformar nuestra extractora; esto ha llevado mucho tiempo de gestión. Uno de los problemas por el que no avanzamos es la indiferencia que tienen algunos productores; pensamos que es pérdida de tiempo y gasto [inversión], queremos que otros hagan [el trabajo] y cuando los compañeros salen a gestionar también está la crítica «de que están paseando y gastando las cooperaciones»; esta forma de ver las cosas dificulta todo. En otras palabras, no queremos hacer las gestiones y cuando otros se ofrecen no aceptamos que están haciendo un esfuerzo (A. Méndez, entrevista, ejido El Arenal, Acapetahua, 25/03/2020).

Desde la subjetividad de las familias, la fidelidad es apropiada y se expresa a través de la entrega de fruta a una sola empresa. Esta forma de concebir la fidelidad supone ponerla en práctica tanto por los socios como por los independientes. Por ser fiel al grupo los beneficios son: el fin de año hay reparto de utilidades; y a largo plazo, el crecimiento y la consolidación incluso de las participaciones 
sociales. A los segundos les permite una gratificación económica y cuando hay mucha producción la garantía de compra de la fruta.

Frutos. En términos de frutos, las unidades familiares visualizan que el sistema productivo de palma africana deberá generar mayores ingresos para cubrir satisfactores inmateriales y materiales que les permitan mejorar su vida. Como personas del medio rural se consideran vulnerables, por lo que es primordial mantenerse saludables para continuar trabajando. También financiar la instrucción escolar de los niños y adolescentes es una prioridad, porque ven en la educación una fuente de inversión. La interacción y el diálogo con las familias permitió observar qué dinámicas económicas y productivas diseñan para obtener más ingresos.

Para los socios el fruto esperado es, a fin de cuentas, extraer más aceite, y a largo plazo también su refinación. Otro fruto esperado es hacer más rentables sus unidades de producción; en algunos casos pasar de 18 a 24 y, en otros, de 24 a 35 toneladas por hectárea.

El orden en el que manifiesta la importancia de los frutos indica que las familias tienen como preocupación central mejorar su capacidad económica no tanto en términos de riqueza material, sino de calidad de vida, y dotar de educación a sus integrantes. Los informantes expresan que el proyecto de palma cumple con todas sus expectativas; no obstante, estas varían considerando que en la microrregión conviven quienes se autodenominan palmero y palmicultor. También la diferenciación se da entre productores independientes y quienes son dueños de una extractora de carácter social.

Actividades económicas. Las características biofísicas de la microrregión costera posibilitan a las familias tener una diversificación productiva amplia. De ese modo, a la prioridad que tiene la palma le siguen, en orden de importancia, el mango, la cría de ganado, la producción de plátano, maíz, frijol y una diversidad de cultivos de traspatio. Estas posibilidades se asocian con la escala de la unidad productiva. Desde la subjetividad, se requiere como mínimo una parcela de 3.5 ha para cultivar palma y otros productos de mayor valor de mercado.

Los productores consideran que ante una crisis del sistema productivo de palma retornarían en primera instancia a la producción de maíz y ganado. En una segunda línea mencionan el plátano y el mango, a pesar de considerarlas actividades de alto riesgo. En el caso de plátano por condiciones meteorológicas, y en el del mango por los altos costos de los insumos, la inestabilidad del precio y las condiciones meteorológicas. 
Dada las circunstancias actuales del mercado internacional de granos básicos, se considera poco probable que con el maíz se pueda obtener un ingreso cercano al que se genera actualmente con la palma. No obstante, la subjetividad del retorno al maíz se asocia con el capital acumulado a lo largo de muchos años de experiencia y a la creencia en que se mantendrán precios de garantía por parte de los organismos gubernamentales.

Capitales. Retomando la propuesta metodológica de Herrera et al. (2017) y Parra et al. (2020) se identifican cinco tipos de capitales: humano, físico, natural, social y monetario. En los talleres fue posible caracterizar cómo los hogares priorizan estos capitales y cómo se asocian con el cultivo de palma.

De los cinco capitales, desde la subjetividad de los hogares se prioriza el social como el más relevante, seguido del económico, el humano, el físico y el natural. El capital social como un proceso de acción colectiva inicia desde la implementación del cultivo. En un primer momento, en la década de 1990, ante la ausencia de una empresa extractora en la microrregión se manifestaron los primeros esfuerzos de acción colectiva por medio de la integración de productores para comercializar el fruto en el municipio de Suchiate, en la frontera México-Guatemala, para que fuera procesado en territorio guatemalteco. Los altos costos de traslado del producto implicaban vender en volumen, por lo que surgieron iniciativas de asociación entre palmicultores para cumplir con las cantidades demandadas y disminuir los fletes. Las unidades productivas que no se vinculaban a estos procesos de comercialización prácticamente tenían que dar por perdida su cosecha.

En un segundo momento, en 1995, producto de los esfuerzos de su organización, los palmicultores negociaron con los gobiernos federal y estatal para establecer dos empresas de tipo social, una en el ejido Arenal y otra en el de Jiquilpan, denominada BEPASA. Según la subjetividad de los productores, la constitución y el respeto de un conjunto de valores por los distintos integrantes les permitió su consolidación. En contraparte, la ausencia de dichos valores entre los integrantes del Arenal llevó a la venta de la extractora.

Ante el éxito de BEPASA, que sirvió como demostración, surgen Zitihualt y La Primavera. Actualmente, ocho organizaciones de siete municipios que van más allá de la propia microrregión de estudio se encuentran en proceso de construcción de Oleopalmex. También se identifican 25 organizaciones de producción rural que con diferentes niveles de consolidación trabajan en algunas de las fases señaladas por Trejo, Valdiviezo y Fletes (2018) para contar con su propia extractora. 
Los valores y la acción colectiva representan elementos fundamentales para emprender proyectos que compitan con las mayores empresas privadas de la microrregión. Al mismo tiempo se reconoce la capacidad de involucrar a distintos actores desde una perspectiva territorial común. Desde la subjetividad de los productores se generan vínculos de cooperación con organizaciones religiosas y políticas de diversa índole, lo que permite consolidar las propias organizaciones sociales de producción e incrementar sus capitales (Bourdieu, 2000). El proceso organizativo basado en la acción colectiva (Melucci, 1991) se liga con el capital del que se dispone. Las primeras iniciativas de construcción de empresas sociales eran mediante la aportación de los socios y del gobierno en sus diferentes niveles.

Para los productores, sus ingresos les posibilitan incursionar en otros cultivos considerados de mayor riesgo, pero que pueden complementar sus entradas. Como se ha señalado previamente, la diversificación se hace en función del tamaño del predio. Según lo que ellos señalan, los ingresos por palma representan la base sobre la cual pueden explorar otros cultivos que en cierto momento son atractivos por su alto precio. Sin embargo, dada la incertidumbre que tienen con respecto a los nuevos cultivos por saturación de mercado y las condiciones meteorológicas, se recurre a mantener la palma como la base de los ingresos.

El grado de diversificación contrasta con las características de monocultivo que tiene la actividad en otros municipios del norte del estado de Chiapas, tal como ocurre en Benemérito de las Américas, Zamora Pico de Oro, Marqués de Comillas, Catazajá y La Libertad, entre otros (Castellanos, 2018; Castellanos y Jansen, 2017; Trejo, Valdiviezo y Parra, 2020). A pesar de que pareciera no estar en riesgo la diversificación productiva, la llegada de nuevas empresas con alta capacidad de procesamiento y demanda sí conlleva un peligro por la acelerada expansión de las áreas de cultivo; además, las empresas promueven el monocultivo y acarrean el consecuente daño ambiental, como ocurre en Sayaxché, Guatemala (Trejo y Valdiviezo, en prensa).

El capital humano representa, desde la subjetividad de los productores, un cúmulo de conocimientos que se pueden obtener por medio de la experiencia, tanto en la actividad en torno a la palma como en la diversificación que ellos emprenden. Por otro lado, el capital humano también se prioriza a través de los recursos orientados a la educación, desde el nivel básico hasta el universitario. La palmicultura posibilita que los hijos se formen a nivel profesional y luego regresen para insertarse en puestos directivos en las empresas sociales y privadas. 
Su capital físico consiste principalmente en la parcela, la maquinaria y los equipos de producción y de transporte. La parcela es una especie de seguro para que, en caso de emergencia, dispongan de los recursos económicos para solventar la situación. Esta es otra forma en que se manifiesta el capital económico al que hace alusión Bourdieu (2000).

Contar con una parcela con palma es garantía de tener dinero; por cualquier necesidad te facilitan dinero, solo tienes que entregar la escritura y chas...chas, te sueltan el dinero; lo puedes empeñar por un mes, seis meses, un año, el tiempo que quieras. Eso sí, a quien le prestes le cedes el derecho de aprovechar la parcela y pagarle el préstamo (P. Ramos, entrevista, ejido Absalón Castellanos, Acapetahua,16/03/2020).

Las familias ven en el cultivo de palma una doble postura: por un lado, como una fuente de ingresos por la venta de la fruta y, por el otro, como una garantía para hacer frente a eventualidades, principalmente en el tema de la salud.

Desde la perspectiva del capital natural las familias palmicultoras admiten que cada una de ellas es responsable de su relación con la naturaleza. Asumen que esto no tiene efectos negativos al interior de la Reserva Ecológica La Encrucijada. Como el Decreto de la Reserva es del 6 de junio de 1995, posterior a la fecha en que ellos inician con la actividad de la palma, no lo consideran como un área que se deba proteger porque, según su opinión, la flora y la fauna nativas están presentes en las áreas de cultivo.

A pesar de que esta es la interpretación desde la subjetividad de los palmicultores, también se reconoce que algunos habitantes de La Encrucijada, principalmente los pescadores, expresan que la palmicultura daña de manera particular la pesca al contaminar severamente los esteros con desechos de las extractoras y también a la propia reserva con la disminución de la diversidad biológica. Sin embargo, los palmicultores aclaran que los cultivos y el procesamiento de la palma no son los únicos que afectan a la reserva ecológica, ya que también se ve seriamente afectada principalmente por otro tipo de plantaciones como el plátano, la caña de azúcar y el mango, por los químicos que utilizan como fertilizantes, fungicidas y plaguicidas.

Estas visiones enfrentadas de los habitantes de la microrregión expresan, por un lado, la posición de los palmicultores sobre los derechos que tienen para hacer uso de los recursos del territorio bajo la premisa de que la actividad no daña el medio ambiente (Godelier, 1984), y que permite mejorar las condiciones de vida de todos los involucrados en el sistema. Lo anterior supone, según los palmi- 
cultores, que la transformación del paisaje en las últimas décadas no tiene efectos nocivos sobre el territorio. En contraste, los pescadores interpretan desde la subjetividad el paisaje como un territorio que ha sido dañado por la interacción social vinculada a la palma africana (Mazzoni, 2014).

Desde el punto de vista de lo modos de vida se puede sintetizar que las familias sienten que desde la llegada de la palma africana se ha propiciado una mejor calidad de vida. No obstante, esta dependerá de las oportunidades que tengan las familias para cubrir sus necesidades básicas.

Antes de que llegara la palma a nuestras vidas vivíamos en la vil pobreza, nuestras casas eran de varitas, los caminos lodazales, era una calamidad vivir aquí. Ahora podemos decir que la pared de nuestras casas es de material y techo de lámina; cooperando y trabajando en conjunto hemos compuesto los caminos: ahora son de terracería; el lodazal ya no se ve como antes. El piso de nuestras casas es de cemento, no en todo, solo en lo necesario; en el lugar de dormir lo tenemos con piso de cemento $(O$. de la Cruz, entrevista, ejido Jiquilpan, Acapetahua, 25/03/2020).

Otra forma en que se interpretan los beneficios de este cultivo:

con la llegada de la palma todos, todos nos hemos beneficiado, palmeros o no; inclusive hasta los que la ven como un cultivo malo. El que mata una res la vende el mismo día, no se le queda, como le pasaba antes. La tienda de abarrotes vende más, las de ropa, el mecánico, las gasolineras, hasta los Oxxos y Elektras, todos, todos (sic) (taller, ejido Paxtal, Villa Comaltitlán, 09/03/2020).

Si bien se observa que el cultivo les ha permitido tener mejor calidad de vida y certeza ante posibles eventualidades, es necesario enfatizar la importancia de la participación colectiva. Al mismo tiempo se reconoce que aquellos que no se involucren en los procesos de acción colectiva quedarán en la escala más baja del sistema y, por lo tanto, estarán en peores condiciones para aprovechar lo que las unidades familiares denominan los beneficios de la palma.

\section{Conclusiones}

La producción y el procesamiento de palma africana en la microrregión costera ha permitido a las unidades familiares adecuar sus modos de vida. Las familias interpretan que la producción de aceite resulta fundamental para determinar la 
base de su fuente de ingresos, que se asocia con la escala del predio y con la forma en que se autodefinen como palmeros, palmicultores o empresarios. Los ingresos económicos ofrecen la posibilidad de emprender procesos de diversificación productiva e incorporar cultivos de mayor riesgo. De manera adicional, permiten fortalecer el capital social y humano, invertir para alcanzar un nivel educativo que refuerce el núcleo familiar y el sistema de palma en conjunto.

Desde la subjetividad, los valores tienen un papel fundamental en las estrategias de vida. Han sido la base de la acción colectiva de los palmicultores. Les han posibilitado incursionar en proyectos de gran envergadura, y eso ha contribuido en la transformación de productores a empresarios. La acción colectiva ha generado la creación de empresas sociales y la opción de apropiarse de un mayor porcentaje del valor generado en el sistema de palma; nuevos mecanismos de autofinanciamiento; proyectos que trascienden a la microrregión y poner en la agenda pública los problemas que enfrenta el sistema productivo.

A pesar de la perspectiva favorable que tienen las familias, los nodos gobierno-empresa y grupo de acción local ejercen el control sobre el sistema productivo. Los organismos multisituados juegan un doble papel, introducen reglas y normas que provienen del ámbito internacional para mejorar aspectos socioambientales del sistema, pero también son los encargados de supervisar su cumplimiento. Las familias involucradas en el cultivo cuestionan el papel de estos organismos porque favorecen a las empresas privadas que demandan el aceite.

Además del doble papel que juegan la RSPO, Solidaridad y Eartworm, resulta cuestionable que estos organismos, que en sus principios predican preservar los derechos de todos los participantes del sistema productivo, reciban financiamiento de las empresas nacionales y multinacionales relacionadas con la demanda del aceite de palma y, por lo tanto, se afanen en mejorar la cuestionada imagen de la cadena productiva.

La consolidación del sistema productivo de palma con la apertura de nuevas empresas extractoras y la posibilidad de refinamiento del aceite representa un riesgo ambiental considerable que puede afectar la diversificación productiva a nivel de parcelas y del territorio en conjunto, así como la concentración de tierras en manos de las empresas privadas, y de ese modo cambiar radicalmente el paisaje actual. 


\section{Agradecimientos}

Este trabajo se realizó como parte de la estancia posdoctoral de Enrique de Jesús Trejo Sánchez, en el Departamento de Agricultura Sociedad y Ambiente de El Colegio de la Frontera Sur unidad San Cristóbal, que fue financiada por el Consejo Nacional de Ciencia y Tecnología (Conacyt) en el periodo agosto de 2019 a julio del 2020. Número de convenio 2019-000006-01NACV-00259.

Externamos un agradecimiento especial a los participantes de los talleres y a actores que proporcionaron información, de manera especial a las familias productoras de palma de aceite.

También queremos agradecer a los dictaminadores anónimos, quienes revisaron cuidadosamente este documento; sus sugerencias nos permitieron mejorar la presentación y los resultados de la investigación realizada. No obstante, los errores y omisiones que pudieran existir en el trabajo son responsabilidad exclusiva de los autores.

\section{Bibliografía}

Abrams, Jesse, Erin C. Pischke, Azahara Mesa-Jurado, Amarella Eastmond, Chelsea Silva y Cassandra Moseley (2019). Between environmental change and neoliberalism: the effects of oil palm production on livelihood resilience. Society \& Natural Resources, 32 (5), pp. 548-565, doi: 10.1080/08941920.2018.1544678

Ávila Romero, Agustín y Jadson Albuquerque. (2018). Impactos socioambientales del cultivo de palma africana: los casos mexicanos y brasileños. Economía y Sociedad, pp. 63-83, doi:10.15359/eys.23-53.4

Bennett, Aoife, Ashwin Ravikumar, Constance McDermott y Yadvinder Malhi. (2019). Smallholder Oil Palm Production in the Peruvian amazon: Rethinking the Promise of Associations and Partnerships for Economically Sustainable Livelihoods. Frontiers in Forest and Global Change, 2, 14, doi:10.3389/ffgc.2019.00014

Bourdieu, Pierre. (2000). Las formas del capital. Capital económico, capital cultural y capital social. En Poder, derecho y clases sociales (pp. 131-164). Bilbao: Desclée de Brouwer.

Castellanos Navarrete, Antonio. (2018). Palma de aceite en tierras campesinas: la política de las transformaciones territoriales en Chiapas, México. Revista Pueblos y fronteras digital, 13, pp. 1-34, disponible en: https://www.pueblosyfronteras.unam.mx/index. php/index.php/pyf/article/view/357/576, doi:10.22201/cimsur.18704115e.2018. v13.357

Castellanos Navarrete, Antonio y Kees Jansen. (2015). Oil palm expansion without enclosure: smallholders and environmental narratives. Journal of Peasant Studies, 42(34), pp. 791-816, doi: 10.1080/03066150.2015.1016920 
Castellanos Navarrete, Antonio y Kees Jansen. (2016). Is Oil palm Expansion a Challenge to Agroecology? Smallholders Practising Industrial Farming in Mexico. Journal of Agrarian change, 18(1), pp. 132-155, doi: 10.1111/joac.12195

Castellanos Navarrete, Antonio y Kees Jansen. (2017). Why do smallholders plant biofuel crops? The 'politics of consent'in Mexico. Geoforum, 87, pp. 15-27, doi:10.1016/j. geoforum.2017.09.019

Castellanos Navarrete, Antonio, William Tobar-Tomás y Carlos López-Monzón. (2019). Development without change: Oil palm labour regimes, development narratives, and disputed moral economies in Mesoamerica. Journal of Rural Studies, 71, pp. 169-180, doi:10.1016/j.jrurstud.2018.08.011

Cernea, M. M. (1991). Putting people first. Sociological variables in rural development. Washington: The World Bank, disponible en: http://documents1.worldbank.org/curated/en/161691468765016390/pdf/multi-page.pdf.

Chambers, R., y G. R Conway. (1991). Sustainable rural livelihoods: practical concepts for the 21st century. IDS Discussion Paper, 296, disponible en: https://opendocs.ids. ac.uk/opendocs/bitstream/handle/20.500.12413/775/Dp296.pdf?sequence=1

Consejo de Europa. (2000). Convenio europeo del paisaje. España: Universitat Politecnica de Valencia, disponible en: http://www.upv.es/contenidos/CAMUNISO/info/ U0506103.pdf

Cook, C. (1991). Social Analysis in Rural Road Proyects. En M.M Cernea (Ed.), Putting people first. Sociological variables in rural development (pp. 397-427). Washington: World Bank/Oxford University Press.

Cruz Morales, Juana (Ed). (2018). Familia y vida campesina en la frontera sur: caminos de escucha transdisciplinarios. Estado de México: Universidad Autónoma Chapingo, disponible en: https://www.researchgate.net/publication/329827631_Familia_y_ vida_campesina_en_la_frontera_sur_caminos_de_escucha_transdisciplinarios

Delabre, Izabela y Chukwumerije Okereke. (2019). Palm oil, power, and participation: The political ecology of social impact assessment. Nature and Space, pp. 642-662, doi: $10.1177 / 2514848619882013$

Department for Intertational Development, D.F. (1999). Sustainable livelihoods guidance sheets, disponible en: http://files.ennonline.net/attachments/871/dfid-sustainable-livelihoods-guidance-sheet-section1.pdf

Earthworm. (2020). Earthworm, disponible en: https://www.earthworm.org/

Echanove Huacuja, Flavia. (2016). La expansión del cultivo de la soja en Campeche, México: Problemática y perspectivas. Anales de Geografía de la Universidad Complutense, pp. 49-70, disponible en: doi:10.5209/rev_AGUC.2016.v36.n1.52713

Godelier, Maurice. (1984). Territorio y propiedad en algunas sociedades precapitalistas. En M. Godelier, Lo ideal y lo material (pp. 95-150). España: Taurus Humanidades, disponible en: https://edisciplinas.usp.br/pluginfile.php/2076923/mod_resource/ content/0/Godelier_Maurice_Lo_ideal_y_lo_material.pdf

Herrera, Obeimar B., Manuel Parra, Iris Livscovsky, Pedro Ramos y Daniela Gallardo. (2017). Lifeways and territorial innovation: values and practices for promoting collective appropriation of territory. Oxford University Press and Community Development Journal, pp. 427-445, doi:10.1093/cdj/bsx052 
Hunsberger, Carol, Simon Bolwig, Esteve Corbera y Felix Creutzig. (2014). Livelihood impacts of biofuel crop production: Implication for governance. Geoforum, pp. 248260, doi:10.1016/j.geoforum.2013.09.022

Isaac-Márquez, Ricardo. (2021). La expansión del cultivo de la palma de aceite en Campeche. De los pequeños productores a la agroindustria transnacional. Región y Sociedad, pp. 1-28, doi:10.22198/rys2021/33/1370

Leff, Enrique. (2006). La ecología política en América Latina. Un campo en construcción. En Héctor Alimonda (Coord.). Los tormentos de la materia. Aportes para una ecología política latinoamericana (pp. 21-39). Buenos Aires: Consejo Latinoamericano de Ciencias Sociales, disponible en: http://biblioteca.clacso.edu. ar/clacso/gt/20101002070402/3Leff.pdf

Mazzoni, Elizabeth. (2014). Unidades de paisaje como base para la organización y gestión territorial. Estudios Socioterritoriales, pp. 51-81, disponible en: http://www. scielo.org.ar/scielo.php?script=sci_arttextypid=S1853-43922014000300004

Melucci, Alberto. (1991). La acción colectiva como construcción social. Estudios Sociológicos, pp. 357-364, disponible en: https://estudiossociologicos.colmex.mx/ index.php/es/article/view/911/911

Mosquera, Mauricio y Daniel López. (2017). Aceite de palma certificado sostenible: análisis de la cadena de valor. Revista Palmas, pp. 11-25. disponible en: https://publicaciones.fedepalma.org/index.php/palmas/article/view/12042/11996

Parra Vázquez, Manuel. (2018). Valores y frutos esperados. En Juana Cruz-Morales (Ed.), Familia y vida campesina en la frontera sur: caminos de escucha transdisciplinarios (pp. 17-21). Estado de México: Universidad Autónoma Chapingo, disponible en:https://www.researchgate.net/publication/329827631_Familia_y_vida_campesina_en_la_frontera_sur_caminos_de_escucha_transdisciplinarios

Parra Vázquez, Manuel, Mario González Espinosa, José Nahed Toral, Luis García Barrios, Eduardo Bello Baltazar, Erin Estrada Lugo y Juana Cruz-Morales. (2020). Respuestas de los grupos domésticos rurales a las intervenciones de los regímenes territoriales en la frontera sur de México. En Luis E. García Barrios, Eduardo Bello Baltazar y Manuel Parra Vázquez (Eds.), Cambio social y agrícola en territorios campesinos. Respuestas locales al régimen neoliberal en la frontera sur de México. San Cristóbal de Las Casas, Chiapas: El Colegio de la Frontera Sur.

Pérez Pérez, Eliezer y Daniel Villafuerte Solís. (2021). Cambios en la dinámica de la economía campesina a partir de la adopción de la palma de aceite en el Soconusco, Chiapas. Entre Diversidades, pp. 92-118, doi:10.31644/ED.V8.N1.2021.A05

Pietilainen, Emma y Gerardo Otero. (2018). Power and dispossession in the neoliberal food regime: oil palm expansion in Guatemala. The Journal of Peasant Studies, pp. 1142-1166, doi:10.1080/03066150.2018.1499093

Rist, Lucy, Laurène Feintrenie y P. Levang. (2010). The livelihood impacts of oil palm: smallholders in Indonesia. Biodivers Conserv, doi: 10.1007/s10531-010-9815-z

Rosas Urióstegui, Faustino, Juan Manuel Pat Fernández, Lucio A. Pat Fernández y Johannes Cornelis van der Wal. (2018). The effect of oil palm on income strategies and food security of households in rural communities in Campeche, Mexico. Acta Universitaria, pp. 25-39, doi: 10.15174/au.2018.1553 
Roundtable on Sustainable Palm Oil (RSPO). (2018). Mexican National Interpretation of the RSPO Principles and Criteria for the Production of Sustainable Palm oil 2018, disponible en: https://www.rspo.org/resources/certification/rspo-national-interpretations/ national-interpretation-p-c-2018/mexico

Scoones, lan. (2009). Livelihoods perspectives and rural development. The Journal of Peasant Studies, 36, pp. 171-196, doi: 10.1080/03066150902820503

Secretaría de Agricultura y Desarrollo Rural (SADER). (2020). Impulsarán Sader y productores de palma de aceite medidas de sustentabilidad para el desarrollo del cultivo en el sur sureste disponible en: https://www.gob.mx/agricultura/prensa/impulsaran-sader-y-productores-de-palma-de-aceite-medidas-de-sustentabilidad-para-el-desarrollo-del-cultivo-en-el-sur-sureste

Servicio de Información Agroalimentaria y Pesquera (SIAP). (2020). Anuario Estadístico de la Producción Agrícola, disponible en: https://nube.siap.gob.mx/cierreagricola/

Solidaridad. (2020). Palma, disponible en: https://www.solidaridadsouthamerica.org/es/ palma

Trejo Sánchez, Enrique de Jesús. (2018). Reestructuración productiva y gobernanza en la cadena de palma de aceite en la microrregión costera de Chiapas de 1990-2015. Tesis de doctorado. Chiapas: Universidad Autónoma de Chiapas, disponible en: https://repositorio.unach.mx/jspui/handle/123456789/3146

Trejo Sánchez, Enrique de Jesús, Guillermo Valdiviezo Ocampo y Héctor Fletes Ocón. (2018). Reestructuración productiva: el caso de la palma de aceite en la microrregión costera de Chiapas. En Héctor Fletes, Perla Vargas e Hilda Jiménez (Eds.), Actores, reconfiguración socioterritorial y desarrollo en Chiapas (pp. 77-105). Chiapas, México: Universidad Autónoma de Chiapas.

Trejo Sánchez, Enrique de Jesús, Guillermo Valdiviezo Ocampo y Manuel Parra Vázquez. (2020). Governance of the system for producing African palm, and the lifeways of participants in two municipalities of the jungle. En Minerva Arce, Manuel Parra, Eduardo Bello y Luciana Gómez (Eds.), Socio-environmental Regimes and Local Visions-Transdisciplinary Experiences in Latin America (p. 24). Inglaterra: Springer.

Trejo Sánchez, Enrique de Jesús y Guillermo Valdiviezo Ocampo. (En prensa). Gobernanza en el sistema de palma de aceite en territorios fronterizos. Los casos de México y Guatemala. México: Universidad Autónoma de Chiapas/Universidad Católica del Uruguay/Universidad de Nayarit/Comunicación Científica Editores.

Valero, Jessica, Héctor Cortina y Coiffier Vela. (2011). El proyecto de biocombustibles en Chiapas: experiencias de los productores de piñón (Jatropha curcas) en el marco de la crisis rural. Estudios Sociales, 19(38), pp. 120-144, disponible en: http://www. scielo.org.mx/scielo.php?script=sci_arttextypid=S0188-45572011000200005

Vázquez González, Lilia, Manuel Parra Vázquez y María A. Gracia. (2018). Transformaciones en la agricultura de los mayas peninsulares: un contraste de los casos de Kampocolché y Xohuayán. Mundo Agrario, 19(41), e084pp. 1-18. doi: 10.24215/15155994e084 


\section{Cómo citar este artículo:}

Trejo Sánchez, Enrique de Jesús, Guillermo S. Valdiviezo Ocampo y Manuel Roberto Parra Vázquez. (2021), «Subjetividades en las estrategias de vida de las familias productoras de palma africana e la microrregión costera de Chiapas». Revista Pueblos y fronteras digital, 16, pp.1-33, doi: 10.22201/cimsur.18704115e.2021.v16.539 